\title{
¿Qué es la comunicación? Proyecto de innovación docente en la asignatura de Introducción al Marketing
}

\author{
MARCO CASTIGLIONI \\ mcastiglioni@us.es \\ Universidad de Sevilla \\ Departamento de Administración de Empresas y \\ Comercialización e Investigación de Mercados \\ mcastiglioni@us.es \\ D.O.I.: http://dx.doi.org/10.12795/JDU.2018.i01.06 \\ Pp.:115-131
}

\section{Resumen:}

En la presente comunicación se presenta un modelo de innovación docente del tema 7 y 8 de la asignatura Introducción al marketing del Grado de en Administración y Dirección de Empresas. A lo largo de la comunicación se muestra como un modelo clásico de transmisión evoluciona para convertirse en un modelo híbrido de enseñanza que incluye elementos de múltiples modelos metodológicos.

Palabras Claves: Marketing; Modelo Transmisión; Modelo Teoría-Practica; Modelo de reelaboración de las ideas de los estudiantes 


\section{Contexto de la asignatura}

La asignatura en la que he aplicado los dos ciclos de mejora se denomina Introducción al marketing, asignatura del primer curso del Grado en Administración y Dirección de Empresas que se imparte en el segundo cuatrimestre.

La asignatura es impartida por 10 profesores que se reparten entre 13 grupos de aproximadamente 80 alumnos por grupo en tres distintos grados (Grado en Administración y Dirección de Empresas, Doble Grado en Derecho y en Economía y Doble Grado en Administración y Dirección de Empresas y en Derecho).

La asignatura tiene dos tipos de clase. En primer lugar, clases teóricas en las que el profesor presenta la parte teórica de la asignatura siguiendo un manual común para todos los grupos, y, en segundo lugar, clases prácticas en las cuales los alumnos realizan problemas de naturaleza matemática vinculados con el marketing, como por ejemplo calcular la demanda de un producto o su elasticidad.

La asignatura no tiene evaluación continua, sino que los alumnos se evalúan en un examen final que se compone de dos partes, una teórica y una práctica.

Como esta ha sido mi primera experiencia docente en esta asignatura, no tenía un modelo que mejorar, sino que tuve que aprender previamente la asignatura y construirme un modelo docente. Afortunadamente para mí, la asignatura está bien estructura y sigue a nivel de contenido que sigue un modelo que yo defino a "embudo", es decir la asignatura empieza con un contenido más general y termina con contenido cada vez más específico.

Al tener que impartir las sesiones teóricas de la asignatura, he utilizado como modelo metodológico el clásico modelo de transmisión (De Alba-Fernández y Porlán-Ariza, 2017), modelo en el que el docente explica el contenido teórico a sus estudiantes. Otra razón por la que he decido utilizar este modelo ha tenido que ver con mi experiencia previa como estudiante: este modelo resultaba ser el modelo que más apreciaba cuando era estudiante.

Para ayudarme a explicar el contenido de la asignatura utilicé unas transparencias en PowerPoint que me 
han sido proporcionadas por el coordinador de la asignatura. Del mismo modo, a lo largo de la asignatura he utilizado preguntas tipo-test de exámenes anteriores a modo de repaso del contenido de la asignatura y para que los alumnos se acostumbraran a la tipología de preguntas del examen.

Cabe destacar que, para amenizar la clase a mis estudiantes, he intentado presentar a los alumnos a lo largo de toda la asignatura ejemplos reales (campañas de marketing de empresas) y cercanos a ellos (campañas de marketing actualmente vigentes en España) que pudieran representar el contenido teórico de la asignatura.

\section{Diseño previo del ciclo de mejora docente}

\section{Mapa de contenidos}

Apliqué el segundo ciclo de mejora sobre dos temas (Temas 7 y 8) que en su conjunto abarcan una de las cuatro P del marketing mix de una empresa: la comunicación. Estos dos temas no resultan especialmente complejos, debido a que su contenido resulta familiar a los alumnos (en los temas se habla de publicidad, promociones, relaciones públicas, etc.) y de sentido común, es decir contenido que puede ser el resultado de un razonamiento relativamente sensato. A pesar de eso, estos temas resultan, en mi opinión, demasiado extensos, aportan contenido excesivamente teórico y no resultan adecuados para un estudiante que se encuentra en el primer año de carrera.

Debido a la extensión del tema al que he aplicado al ciclo de mejor, he dibujado dos mapas de contenido. En el primer mapa se aprecia como el tema objeto del ciclo de mejora se relaciona con los demás temas de la asignatura. En este primer mapa también aparecen los valores de la asignatura. A lo largo de la asignatura, cada vez que empezaba un nuevo tema repetía el modelo teórico general de toda la asignatura y mostraba a los estudiantes como el 
nuevo tema se iba a relacionar con los temas anteriores. Del mismo modo, en cada tema intentaba subrayar los valores generales de asignatura y cómo estos valores se aplicaban en lo especifico en cada tema.

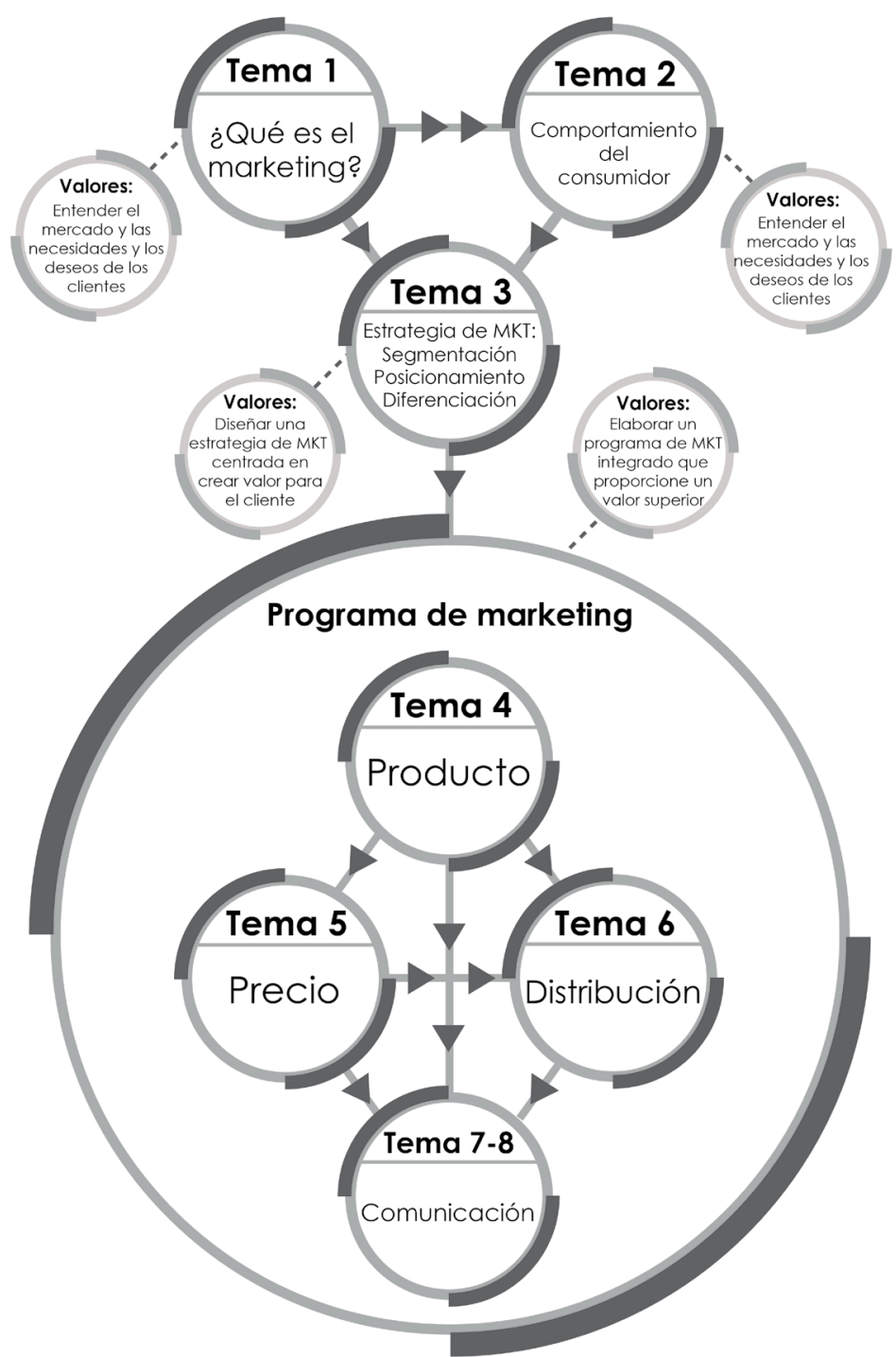

Figura 1. Mapa de contenidos general de la asignatura

En el segundo mapa aparecen los contenidos del tema objeto del ciclo de mejora.

Jornadas de Formación e Innovación Docente del Profesorado | № 1 (2018) (i) Esta obra se distribuye con la licencia Creative Commons 


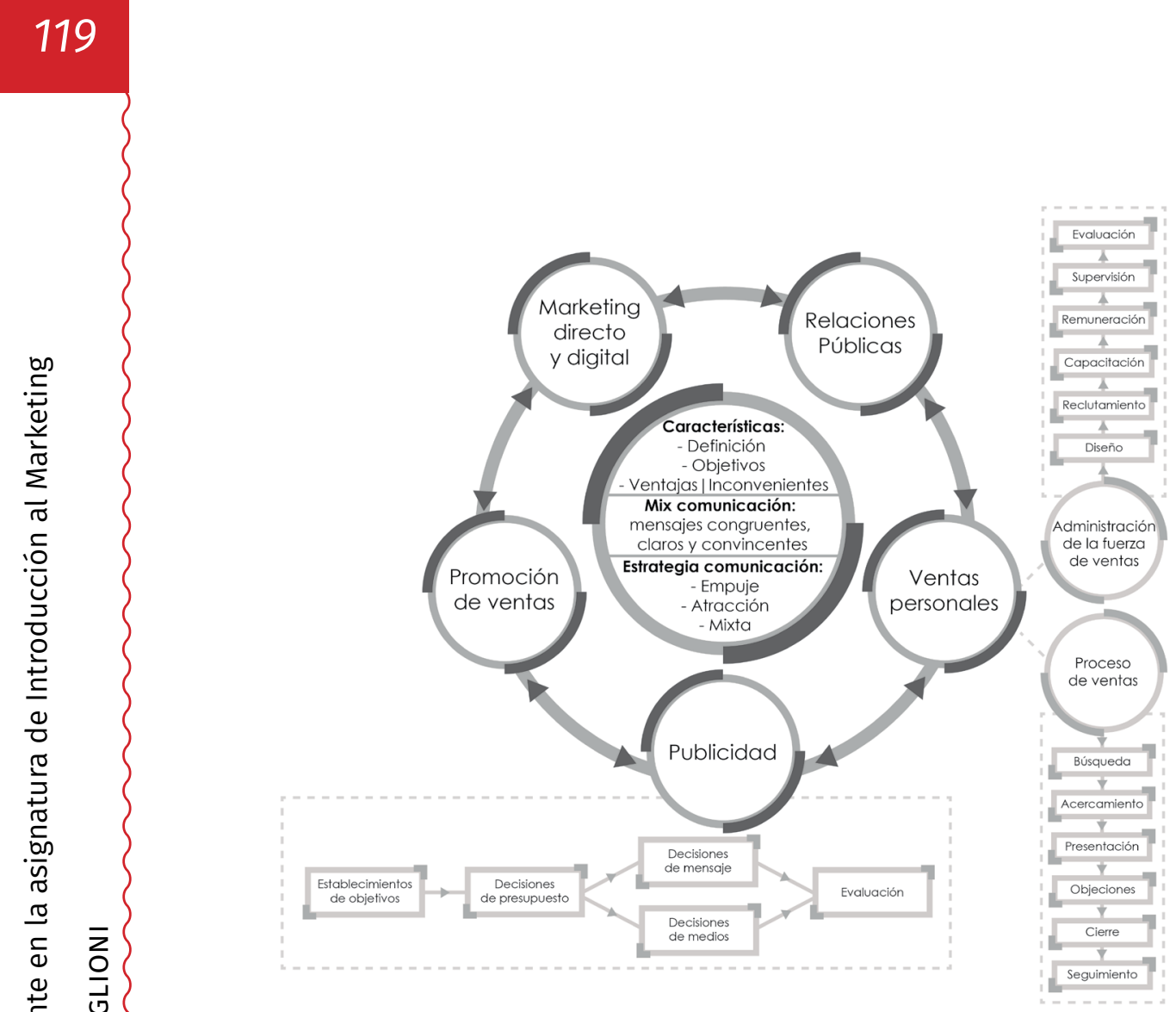

Figura 2. Mapa de contenidos del segundo ciclo de mejora.

Al plantearme el ciclo de mejora he detectado los siguientes problemas a nivel de clase: 1) falta de interés y atención por parte de los estudiantes; 2) falta de actitud por parte de los estudiantes. Con el primer y el segundo ciclo de mejora, he intentado enfrentarme al primer problema, mientras que el segundo problema no he sabido cómo enfrentarlo. 


\section{Diseño previo del ciclo de mejora docente}

\section{Modelo metodológico posible y secuencia de actividades programada}

En función del problema de falta de interés y atención que había detectado en clase, he intentado aportar los siguientes cambios a mi modelo metodológico de enseñanza basado en la transmisión para intentar que las clases resulten más entretenidas y más interesantes para los alumnos.

En primer lugar, decido introducir más ejemplos de campañas de marketing para que los estudiantes vieran como la teoría se convierte en la práctica empresarial. En segundo lugar, he intentado desarrollar parte del contenido teórico de las dos sesiones del ciclo de mejora a partir del dialogo y de la interacción con la clase, es decir, he intentado definir cuales preguntas realizar a la clase para que a través de sus respuestas ellos pudieran determinar la teoría subyacente. En tercer lugar, decido buscar contenido audiovisual y noticias de prensa que puedan sustituir parte del contenido teórico. Finalmente, decido introducir el tema objeto del ciclo de mejora (la comunicación) no siguiendo el esquema propuesto por el libro de texto sino apoyándome por el conocimiento previo de los alumnos.

Una vez determinados estas metodologías de enseñanzas alternativas al modelo clásico de transmisión, preparo las dos sesiones del ciclo de mejora intentando identificar, utilizando el mapa de contenido de los temas 7 y 8 , el contenido adecuado por cada metodología que iba a utilizar.

Decido, por tanto, planear el comienzo de la clase haciendo una pequeña introducción sobre la comunicación y su importancia que no aparece en el libro de texto y en el programa de la asignatura. Decido añadir este contenido extra a la asignatura por tres razones: 1) considero que puede resultar interesante para los alumnos, 2) el 
contenido sirve para aclarar el contexto en el que se encuentra enmarcado el tema objeto el ciclo de mejora, y 3) para este contenido extra resulta posible utilizar el conocimiento previo de los alumnos.

Después de esta introducción, siguiendo el esquema del capítulo y el mapa de contenido, me propongo intentar definir a través del dialogo y de una serie de preguntas la primera parte del tema 7 , parte en la que se analiza el mix de comunicación de una empresa.

La última parte de la parte de la primera sesión es dedicada a analizar más en detalle uno de los elementos de la comunicación: la publicidad. Al plantearme cómo enfrentarme a esta parte, decido utilizar el ejemplo de una famosa campaña publicitaria para presentar los posibles problemas de la publicidad. Del mismo modo, planifico explicar otra parte del contenido vinculado a la publicidad (la determinación del presupuesto publicitario), haciendo "ingeniería inversa", es decir, yo planteo a la clase distintos ejemplos de cómo los jóvenes pueden determinar su presupuesto para salir un viernes por la noche y en función de mis ejemplos espero que la clase pueda determinar la teoría subyacente.

Finalmente, quiero destacar como en esta última parte de la primera sesión decido explicar parte del contenido utilizando el modelo clásico de transmisión.

A la hora de planificar la segunda sesión del ciclo de mejora (tema 8), centrada en las ventas personales y en la promoción de ventas, busci una noticia que había leído hace un par de años y que me resultó interesante: una persona se dedicaba casi profesionalmente a ganar los premios de las distintas promociones de las marcas comerciales.

Al planear la parte dedicada a las ventas personales obtengo como sugerencia de un compañero de la asignatura que ponga unos videos en clases. Al ver los videos y considerarlos idóneos decido usarlos para sustituir parte del contenido teórico. Adicionalmente planifico explicar el 
proceso de venta de los vendedores usando como ejemplo para la clase el caso de los vendedores de coche presentes en las concesionarias.

Cabe destacar como también en esta segunda sesión decido explicar parte del contenido utilizando el modelo clásico de transmisión.

La descripción de como he aplicado cada uno de estos seis principios en concreto, aparece en el relato de las dos sesiones del ciclo de mejora.

\section{Cuestionario inicial-final}

He realizado un cuestionario para analizar la evolución de mis estudiantes compuesto por tres preguntas abiertas, evitando preguntar por información académica como recomendado por Rivero-García y Porlán-Ariza (2017).

Las preguntas del cuestionario han sido las siguiente:

- ¿Qué es para ti la comunicación? ¿Por qué la comunicación es importante para una empresa?

- A nivel de empresa, ¿qué relación tiene la comunicación con las otras variables del marketing mix que hemos visto en los temas previos?

- ¿Puedes proponer ejemplos de las distintas formas de comunicación de una empresa? ¿Cómo clasificarías las múltiples formas de comunicación que maneja una empresa?

He decidido realizar sólo estas preguntas para analizar la evolución de los estudiantes debido a que he aprovechado el cuestionario para conocer mejor a mis estudiantes y para saber qué piensan de la asignatura, ya que este ha sido mi primer año como profesor de la asignatura. Del mismo modo he añadido una sección de carácter general dedicada al conocimiento previo para evaluar como llevaban el estudio de la asignatura a muy pocos días del examen final (la sesión en la que pasé la encuesta a los estudiantes tuvo lugar 8 días antes del examen). Estás secciones que he añadido en el cuestionario me han 
proporcionado información sumamente interesante que usaré para realizar comentarios en la sección de evaluación del ciclo de mejora realizado.

\section{Aplicación del ciclo de mejora docente}

El ciclo de mejora se ha desarrollado a lo largo de dos clases. A continuación, voy a resumir las dos sesiones.

Primera sesión (clase del lunes 28 de mayo de 2018). Al entrar en clase saludo los alumnos, y les comunico que antes de explicar el tema 7 de la asignatura iban a realizar un pequeño cuestionario anónimo vinculado con el curso de innovación docente en el que estaba participando. Al tener solamente 8 alumnos en la clase decido que el segundo cuestionario (el cuestionario final) lo iba a pasar al final de esta primera sesión debido a que los alumnos pueden no estar presente en la segunda sesión. Después de 15 minutos retiro el cuestionario y empiezo a explicar el tema 7. Como comenté anteriormente, este tema vierte sobre la comunicación de la empresa. En lugar de empezar explicando la teoría, decido introducir el tema no siguiendo el esquema propuesto en el libro de texto sino pidiendo a los alumnos que me ayuden a desarrollar en la pizarra el clásico modelo de comunicación (emitente, receptor, canal y mensaje) que han visto previamente en bachillerato. Esta introducción, con un resultado muy positivo, me sirve para que los alumnos comprendan por qué es importante la comunicación para una empresa: para transmitir su mensaje al mercado de clientes potenciales.

Después, de haber introducido el concepto de comunicación y su importancia para la empresa, intento que los estudiantes puedan determinar a través de una serie de preguntas que les hago el mix de comunicación que puede tener una empresa (las distintas formas de comunicación de la empresa). Una vez determinado el mix de comunicación de la empresa, siempre a través de una serie de preguntas y dialogando con la clase determinamos 
de forma colegial la definición de cada forma de comunicación, el contexto en el que es usada, sus ventajas y sus desventajas.

Después de determinar el mix de comunicación de la empresa, les explico teóricamente y con ejemplos la estrategia de comunicación de la empresa al no encontrar una forma en que los estudiantes pudieran determinar por si sólo las distintas estrategias que puede utilizar una empresa.

A continuación, dedico la última parte de la clase a los tres primeros elementos del mix de comunicación: publicidad, marketing directo y relaciones públicas. Junto con la clase definimos los elementos principales de cada una de estas formas de comunicación y después de eso comunico a la clase que los detalles concretos de cada forma de comunicación tendrán que aprenderlos de manera autónoma debido a que es contenido que presenta un grado de dificultad muy bajo. En esta última parte de la clase además de proporcionar ejemplo a la clase utilizo herramientas audiovisuales para mantener la atención de los estudiantes. Por ejemplo, para ilustrar las posibles desventajas y errores de la publicidad propongo a la clase el caso de la campaña de verano de la cerveza Estrella Damm y les muestro el video del verano de 2017.

Antes de finalizar la clase comunico a los alumnos que en la siguiente sesión íbamos a presentar y resolver las preguntas tipo test de los temas 7 y 8 y que, por tanto, hicieran el esfuerzo de leer dichos temas antes de la siguiente clase. Después de eso, les entrego el cuestionario final de evaluación para que lo realicen en clase, aunque esta vez sólo tienen que responder a las tres preguntas vinculadas con los temas 7 y 8 .

Segunda sesión (clase del miércoles 30 de mayo de 2018). Al entrar en clase saludo los alumnos, y les comunico que, como habíamos acordado, antes de explicar el tema 8 iba a presentarles y dar la solución de las preguntas 
tipo test 7 que aparecen en su manual. Por tanto, dedico los primeros veinte minutos de la clase a resolver los tipos test con los alumnos. En esta segunda sesión participan 6 alumnos (4 que habían participado a la primera sesión y 2 que no habían estado en la primera sesión).

Terminado con las preguntas tipo test empiezo a explicar el tema 8. En este tema se trata de los elementos del mix de comunicación de la empresa: fuerza de ventas y promoción de ventas. Empiezo con el primer elemento, la fuerza de venta, y para definir algunos elementos de la teoría propongo a los estudiantes situaciones prácticas que nos ayuden a determinarla. Por ejemplo, en la teoría se habla de cómo es posible organizar la fuerza de venta (geográficamente, por producto y por mercado), en lugar de proporcionarle la teoría le presento situaciones concretas a partir de las cuales ellos mismo determinan la teoría subyacente.

Otra herramienta metodológica que utilizo para mantener el interés y captar la atención de la clase es el uso de videos que puedan sustituir partes de la teoría que considero de escaso interés y "pesadas" para los estudiantes. Por esta razón en lugar de hablar teóricamente sobre cómo contratar al personal de ventas de la empresa y cómo motivarlo, proyecto tres videos: un corto sobre el reclutamiento del personal (de una duración aproximada de 10 minutos) y dos videos sobre motivación del personal, uno sacado de una película (El lobo de Wall Street) y el otro uno sketch cómico. Al terminar cada vídeo aprovecho para crear un pequeño debate en clase para determinar qué han aprendido los estudiantes de los videos, qué elementos de la teoría podemos determinar a partir del video

Al cabo de una hora termino todo el contenido vinculado con la fuerza de ventas y empiezo el contenido relacionado con la promoción de ventas. Para dinamizar la clase hago a los estudiantes la siguiente pregunta: “Creéis que es posible vivir de los premios, sorteos y regalos de los distintos concursos de las marcas comerciales?". La 
clase me contesta de forma unánime que no, entonces yo les presento el caso de un bombero de Mérida que, desde 2003, se dedica a ganar de forma que podríamos clasificar como profesional dichos premios, sorteos y regalos. La clase resulta sorprendida y al comentar la noticia que les propongo se abre un debate sobre la tributación fiscal de los premios y regalos por parte del bombero. Utilizo este caso también para ilustrar la teoría vinculada con la promoción de ventas, ya que en la noticia aparecen las múltiples formas de promoción que puede usar una empresa.

Finalizo la clase al presentar y resolver las preguntas tipo test del tema 8. En la resolución de las preguntas tipo test compruebo que la clase en su conjunto muestra haber comprendido el tema que habíamos desarrollado en esa misma sesión.

\section{Evaluación del aprendizaje de los estudiantes}

He intentado comparar los cuestionarios iniciales y finales para detectar la evolución de mis estudiantes a lo largo del ciclo de mejora, pero he tenido los siguientes problemas. Tres alumnos no han contestado a algunas de las preguntas del cuestionario inicial, por tanto, me ha sido imposible evaluar para ellos su posición inicial en la escalera. Considero el hecho de que decidieron no contestar a las preguntas como una falta de actitud por su parte ya que las preguntas del test eran de carácter general.

El segundo problema está relacionado con el cuestionario final. El análisis de las respuestas del cuestionario final muestra que prácticamente ninguno de los alumnos ha subido los peldaños de la escalera ya que sus respuestas han sido iguales o incluso peores que en el cuestionario inicial. Achaco este empeoramiento de los resultados a una falta de actitud de los estudiantes ya que ellos al ser conscientes de que al finalizar el cuestionario terminaría la clase decidieron contestar de forma apresurada y superficial para poder irse. 
Debido a estos problemas, he usado para evaluar los estudiantes las sensaciones que he tenido al presentar y resolver las preguntas tipo test del tema 8 al final de la segunda sesión. Utilizado este criterio de evaluación me considero muy satisfecho, ya que la clase en su conjunto contesta de forma acertada a las preguntas. Obviamente reconozco que guiarme por sensaciones no es un criterio fiable, pero como he expresado previamente no he considerado que el análisis del cuestionario final resultara viable.

A pesar de eso he intentado averiguar la posición inicial en la escalera de los ocho alumnos que han participado en la primera sesión. En cada pregunta he determinado que los estudiantes se repartían entre los dos primeros peldaños de unas escaleras de cuatro peldaños. Las respuestas de los alumnos han sido muy simple e incompletas. Además, he notado cierta falta de comprensión lectora por su parte, ya que las respuestas no eran acordes con la pregunta. Esto ha sido el caso de la primera pregunta “¿Qué es para ti la comunicación? ¿Por qué la comunicación es importante para una empresa?", casi la totalidad de los alumnos ha contestado a la primera parte de la pregunta usando la óptica de la empresa cuando en realidad era una pregunta mucho más general y abierta. Achaco este error, quizás, a la influencia de la segunda parte de la pregunta en la que sí se hace referencia a una óptica a nivel de empresa.

Al terminar cada una de las dos sesiones me he encontrado muy satisfecho conmigo mismo ya que, en mi opinión, he conseguido el objetivo que me había prefijado, es decir hacer que las clases resultaran más atractivas y entretenidas para los estudiantes para mantener de esa forma su atención y su interés.

A pesar de estar satisfecho a nivel general, hay elementos que me hacen pensar que hay que trabajar más para mejorar la docencia en esta asignatura. A lo largo del curso he madurado la idea que la asignatura en su 
conjunto requiera una reforma radical ya que no es sólo una cuestión de metodología de enseñanza, sino que es mucho más profundo: la asignatura debería replantearse a nivel de contenidos y a nivel de evaluación de los alumnos. Intentaré profundizar estas ideas en la siguiente sección

\section{Evaluación del ciclo de mejora docente}

\section{Cuestiones a mantener y cambios a introducir}

Como comentaba en el apartado anterior, estoy muy satisfecho con mi segundo ciclo de mejora. En este apartado intentaré destacar las cuestiones a mantener y cambiar de cada al futuro.

Considero que resula interesante mantener las siguientes prácticas y herramientas que he utilizado a lo largo de la asignatura. En primer lugar, ha resultado interesante utilizar/apalancar el conocimiento previo de los alumnos (en la medida de lo posible) como en el caso del desarrollo del modelo de comunicación clásico que he usado para introducir el tema de comunicación en la primera sesión de ciclo de mejora. En segundo lugar, me resulta muy útil, la selección del contenido a tratar en clase: no todo el contenido tiene la misma importancia o el mismo nivel de dificultad, además puede ser una forma de fomentar el trabajo individual de los alumnos. En tercer lugar, el uso de herramientas audiovisuales para intentar mantener la atención y el interés de los alumnos ha sido bastante exitoso, aunque hay que dosificar estás herramientas. En cuarto lugar, me ha resultado interesante construir la teoría a partir del dialogo y de la interacción con los alumnos. Esta metodología de enseñanza permite determinar la teoría de la asignatura usando un modelo basado en la reelaboración de las ideas de los estudiantes (De Alba-Fernández y Porlán-Ariza, 2017). El problema surge en el momento en que 
las respuestas que yo recibo a mis preguntas no son las esperada por mi parte, lo que me lleva como profesor a improvisar otras preguntas y a alejarme del sendero lógico que había trazado previamente. Esto determina dos posibilidades: 1) a través de otra serie de preguntas llego al destino que me había prefijado o 2) me atasco y tengo que proporcionar yo la respuesta que considero correcta para llegar a la meta deseada. A pesar de estos posibles problemas, esta metodología me aparece fascinante y creo que sólo requiere más práctica y más experiencia.

Finalmente, los cuestionarios inicial-final me resultan interesantes, sobre todo el cuestionario inicial. Mi problema ha sido la determinación de las preguntas, pero creo que a medida que vaya practicando más y tenga más experiencia podré dominar esta interesante herramienta.

A pesar de estar satisfecho a nivel general, hay elementos que me hacen pensar que hay que trabajar más para mejorar la docencia en esta asignatura. A lo largo del curso he madurado la idea que la asignatura en su conjunto requiera una reforma radical ya que no es sólo una cuestión de metodología de enseñanza, sino que es mucho más profundo: la asignatura debería replantearse a nivel de contenidos y a nivel de evaluación de los alumnos. Creo que el sistema de evaluación afecta la actitud de los estudiantes. Cuando realicé el cuestionario inicial-final estábamos a 8 días del examen final, y 3 de los 8 estudiantes que rellenaron el cuestionario afirmaron no haber empezado a estudiar aún. Esto, para mí, refleja una falta de actitud, si la clase no pone de su parte las innovaciones docentes caen en saco roto. Además, he detectado como muchos alumnos acuden a clase de forma irregular. Creo que este comportamiento se debe, en parte, a la falta evaluación continua ya que los estudiantes reaccionan a los estímulos por parte de su entorno. 


\section{Principios didácticos argumentados que han guiado la experiencia}

He aplicado los dos ciclos de mejora en una asignatura en la que tenía asignada sólo clases de tipo teórico. Por tanto, el modelo que elegi para dar las clases y sobre el que he ido haciendo cambios y modificaciones ha sido el modelo clásico de transmisión (De Alba-Fernández y Porlán-Ariza, 2017).

He intentado modificar y adaptar este modelo de distintas formas para que las dos sesiones de clase resultaran más entretenidas y más dinámicas debido a que detecté un problema de falta de atención e interés. Más en concreto, he proporcionado a los alumnos ejemplos de campañas de marketing de impresas reales para ilustrar de forma practica la teoría de la asignatura. De esta forma, el modelo clásico de transmisión se acerca y asemeja al modelo basado en la teoría y su aplicación a la práctica (De Alba-Fernández y Porlán-Ariza, 2017). Adicionalmente, he intentado desarrollar parte del contenido teórico a través del dialogo y la interacción con la clase, intentando pasar, por tanto, del modelo clásico de transmisión a un modelo basado en la reelaboración de las ideas de los estudiantes (De Alba-Fernández y Porlán-Ariza, 2017). Este modelo utiliza el conocimiento previo de los alumnos para desarrollar el contenido de la asignatura (Rivero-García y Porlán-Ariza, 2017).

Del mismo modo he intentado seleccionar el contenido a presentar y desarrollar en clase, dejando parte de contenido para que los estudiantes se enfrentaran a él de forma autónoma. Esto ha sido posible gracias a la estructura de la asignatura, ya que existe un manual común para todos los grupos. Además, decidí presentar en clase sólo parte del contenido de la asignatura, debido a que consideré que los estudiantes tenían las competencias necesarias para poder entender y asimilar ese contenido que había decido excluir. 
Finalmente, para dinamizar aún más las clases y para captar la atención e interés he utilizado material audiovisual.

Como es posible observar, todos los cambios que he introducido, que derivan de distintos modelos metodológicos, hacen que en las dos sesiones del segundo ciclo de mejora haya utilizado un modelo de enseñanza hibrido que se aleja mucho del clásico modelo de transmisión que usaba previamente a los dos ciclos de mejora.

\section{Referencias ibliográficas:}

De Alba-Fernández, N. y Porlán-Ariza, R. La metodología de enseñanza. Pag. 37-54. En: Enseñanza universitaria. Cómo mejorarla. Barcelona. Morata. 2017.

Rivero-García, A. y Porlán-Ariza, R. La evaluación en la enseñanza universitaria. Pag. 73-91. En: Enseñanza universitaria. Cómo mejorarla. Barcelona. Morata. 2017.

Jornadas de Formación e Innovación Docente del Profesorado | № 1 (2018) Esta obra se distribuye con la licencia Creative Commons 